\title{
Book Review: Designing Effective Instruction
}

\author{
Yavuz Akbulut \\ Anadolu University, Turkey
}

Effective instructional design is a major prerequisite for desired learning outcomes. Even though the field of instructional design (ID) is relatively young, its multidisciplinary and rapidly evolving nature requires meticulous work to implement the most current evidence-based heuristics in instructional settings. The sixth edition of Designing Effective Instruction by G. R. Morrison, S. M. Ross, H. K. Kalman, and J. E. Kemp (Wiley, 2010, 491 pages, ISBN 13: 978-0-470-522820) serves as an invaluable source, which provides instructional designers with the essential guidance to implement these evidence-based heuristics to a variety of instructional problems appropriately. The authors are recognized scholars who have authored numerous contributive studies on instructional design and technology. Morrison has been the senior author of the book since the third edition. In the sixth edition, Kalman has joined the team.

The skeleton of the book evolves from Jerrold Kemp's early textbooks. The model presented in the book considers ID a continuous cycle of nine elements, which are supported by ongoing processes related to planning, implementation and evaluation. An emphasis on designing in business settings is observed which can be distractive for some readers; however, the approach is applicable to professionals in other settings including higher education, p-12 classrooms, and military as well as medical settings. Numerous examples based on authors' professional experiences are provided for different settings which supports the book's focus on the application. Moreover, various pedagogical features were included to stimulate thinking towards the goal of using the ID model for the development of effective instruction. In this regard, an appropriate balance between theory and application is provided since complex issues are integrated into the text with an easyto-follow presentation. For example, at the start of each chapter is a real-world scenario which can be used to trigger classroom discussions. Provided questions guide the readers throughout the chapters. Experiences of leading practitioners and scholars familiarize readers with the real world projects in the "Expert Edge" sections of each chapter. 'The ID Process' pieces show the readers how the heuristics are actually put into practice. At the end of chapters, readers are further provided with exercises and realistic problems. Last but not the least, key issues and questions regarding quality management of the ID projects are included as a separate section in many chapters.

Similar to the ID model provided in the book, the organization of the chapters is somewhat flexible. Almost every chapter looks like an independent reference source in its entirety. That is, a linear reading from cover to cover is not necessary for those who are familiar with the field. On the other hand, the source can be used as a textbook for an introductory course as transitions are very effective and interrelationships between the elements of the model are highlighted very often. The authors also provide readers with suggestions on how to use the book in both 
introductory and advanced courses. The book begins the first chapter by providing readers with an introduction to the ID process, clarifying terminology, discussing the benefits of ID in different settings, examining some of the contexts in which ID works, identifying basic premises underlying the ID process and presenting an overview of the proposed design model. Criticisms of the ID process are also discussed with strong rationales in the first chapter.

Chapters 2 through 13 illustrate the basic design process. Chapter 2 focuses on identification of the need for instruction. Crucial heuristics to conduct needs assessment, goal analysis and performance assessment are discussed in this chapter with a reference to each technique's unique features, and interrelationships among these techniques during the identification of a training problem.

Chapter 3 addresses learner characteristics and contextual factors that should be considered when planning instruction as well as the limitations these may place on the design.

Chapter 4 helps the readers define the content which is needed to address the instructional need, which involves topic, procedural and critical incident analyses. Each method is described, exemplified and supported with steps or cues to enhance the analysis.

Chapter 5 discusses the functions of instructional objectives followed by the taxonomies for cognitive, psychomotor and affective domains. Several hints to develop instructional objectives in different domains are provided with examples along with effective methods to organize and sequence the objectives.

Chapter 6 describes the benefits of using schemes to sequence the instructional content with references to the Posner and Strike (1976) schemes and elaboration theory (English \& Reigeluth, 1996) while the focus is on the former.

Chapter 7 demonstrates the instructional strategies to present the instruction in a meaningful way so that objectives are mastered by each learner. Prescriptions for teaching different content types are provided through examples and implementation suggestions.

Chapter 8 examines the ways to implement the instructional strategies. It identifies guidelines for different preinstructional strategies, which is followed by instructional message design principles for text, pictures and graphics.

Chapter 9 proposes highly valuable guidelines for translating the instructional design plan into instruction. Particularly the discussion on cognitive load is practical and up-to-date. Moreover, guidelines for effective learning in a variety of patterns such as group presentations, self-paced learning and small-group interaction activities are quite useful.

Chapter 10 is a new chapter in this edition, which is about design considerations for technologybased instruction. Affordances of technology-based instruction are discussed followed by a synthesis of computer- or Web-based instruction types, and design considerations for a variety of patterns and settings including individualized computer and web-based instruction and groupbased distance instruction. 
Chapters 11 to 13 focus on evaluation and assessment. Chapter 11 formulates the purposes of evaluation and discusses the relationships among formative, summative and confirmative evaluations. The relationship between evaluation and instructional objectives is explained, validity and reliability concerns are discussed, relative and absolute standards of achievement are explained, and a discussion of student self-evaluation is included.

Chapter 12 synthesizes the ways to develop evaluation instruments or methods to assess different outcomes: Knowledge, skills and behavior, and/or attitudes. Different assessment tools and methods are exemplified followed by development and implementation guidelines.

Chapter 13 proposes guidelines to use formative, summative and confirmative evaluations to assess both developing and completed instructional programs. A basic model for planning formative evaluation is followed by common types and major stages of formative evaluation. Use of summative evaluation to examine program effectiveness and efficiency was discussed; approaches to confirmative evaluation are provided; and reporting the results of these evaluations is explained.

Unlike several other textbooks in the field, theories of learning and instruction are reviewed in Chapter 14. Each learning theory is followed by relevant instructional design principles and example applications. These examples support implementations in previous chapters and justify why this unit can be more meaningful after the first 13 chapters.

Chapter 15 addresses planning for instructional implementation. A discussion on planned change (Bhola, 1982) and innovation theory (Rogers, 1995) is followed by the explanation of the CLER model (Bhola, 1982) as a general framework for developing the implementation plan. Further implementation decision concerns are also discussed with regard to the training of instructors and roles of supervisors.

Chapter 16 describes the key tasks, activities and various roles involved in instructional design project management. Project agreement and proposal preparation steps are exemplified, instructional design in organizations is discussed, working with different stakeholders and team members is explained, and legal considerations in ID project management are underlined.

The ID field requires an eclectic approach since it needs to resort to evidence and borrow ideas from several different disciplines constantly to improve the ID practices. Moreover, it has continuously and rapidly changed in the past decades. In this regard, the authors overcome the challenge of integrating recent trends into the manuscript through critical revisions in each edition. In the sixth edition, for instance, a new chapter is devoted to design considerations for technology-based instruction in which computer-based, web-based and distance instruction were addressed. The planning and implementation and the project management parts are improved. A new section has been added regarding the decision stages in adopting innovations. Supervisors' roles in encouraging employee training are also discussed. All these revisions contribute to the popularity of the model as it is one of the very few models that continue to be modified in accordance with recent developments in related fields. 
The model suggested in the book is basically cognitive and makes use of relevant behavioral guidelines. In addition, the presentation of the model makes it easily adopted by constructivist practitioners. Even though the earlier editions of the current model is exemplified among the classroom-oriented models (Gustafson \& Branch, 2002), the model carries characteristics of product-oriented models particularly in terms of the emphasis on instructional development in a rich variety of contexts and the greater focus on both formative and summative evaluation as continuous processes which influence all decision making and implementation stages. In this regard, it can be argued that the current model looks more product-oriented than classroomoriented.

The chapters highlighted here as isolated chunks are provided in the book with relevant transitions, which empowers the intellectual conversation and reader-friendliness. Even though the flow of reading is almost flawless after six editions and the authors cater to different learner preferences as much as possible, contemplation on practice and given real-world scenarios is strongly advised rather than a fast cover-to-cover reading. In short, this resource serves as a quality reference text to anybody interested in instructional design, and can be used effectively by both novice and expert practitioners in the field.

\section{References}

Bhola, H. S. (1982). Planning change in education and development. The CLER model in the context of a mega model. Viewpoints in Teaching and Learning, 58(4), 1-35.

English, R. E., \& Reigeluth, C. M. (1996). Formative evaluation research on sequencing instruction with elaboration theory. Educational Technology Research and Development, 44 (1), 23-42.

Gustafson, K. L. \& Branch, R. M. (2002). Survey of instructional development models (4 ${ }^{\text {th }}$ Edition). Syracuse, NY: ERIC Clearinghouse on Information \& Technology. Retrieved from ERIC database (ED477517).

Posner, G. J. \& Strike, K. A. (1976). A categorization scheme for principles of sequencing content. Review of Educational Research, 46(4), 665-690.

Rogers, E. M. (1995). Diffusion of innovations (4 ${ }^{\text {th }}$ edition). New York: Free Press.

Correspondence: Yavuz Akbulut, Associate Professor, Department of Computer Education and Instructional Technologies, Faculty of Education, Anadolu University, Yunus Emre Campus, Eskisehir 26470, Turkey 